\title{
CSI Africa Abstracts
}

\section{CSI Africa - December 1-2, 2017}

\section{LARGE PATENT DUCTUS ARTERIOSUS AND SEVERE PULMONARY VALVE STENOSIS \\ Jean Claude Ambassa \\ Shisong Cardiovascular Center' Shisong' Cameroon}

History: $\mathrm{O} 6$ years old female patient, Body weight $22 \mathrm{~kg}$. Systolic and continuous murmurs since birth. Pediatric cardiology assessment at the age of one year. Follow up with repeated airways infections that indicated percutaneous P.D.A. closure and Pulmonary valvuloplasty.

Physical Examination: Systolic murmur on the pulmonary auscultation focuGrade 4-5/6 and continuous murmur under the left subclavian

E.C.G: Right axis deviation, Biventricular hypertrophy.

T.T.E: Biventricular hypertrophy. Good systolic function. Severe pulmonary valve stenosis (dysplasic valve, doming shape, post stenotic dilatation, transvalvular gradient $100 \mathrm{mmHg}$, annulus $18 \mathrm{~mm}$ of diameter. Right ventricular systolic pressure $110 \mathrm{mmHg}$.

Confluent pulmonary artery branches. Fluximetry in the pulmonary artery compatible with large Patent Ductus Arterious $6 \mathrm{~mm}$ of diameter.

Angiography: Profile view severe pulmonary valve stenosis, post stenotic dilatation, annulus $20 \mathrm{~mm}$. Patent ductus arteriosus, $6 \mathrm{~mm}$ diameter.

Intended Procedure: Percutaneous Pulmonary Valvuloplasty and Transcatheter closure of PDA using an Amplatzer ductus occluder type I.

Learning Points: Challenges with the pulmonary valvuloplasty associated with PDA.

\section{DEVELOPING A CARDIO-SURGICAL CENTER IN CENTRAL AFRICA: THE CAMEROON EXPERIENCE Jean Claude Ambassa,MD', Alfred Kongnyuy, SRN', Fanka Marcel, SRN', Jacques Cabral Tantchou,MD, PHD', Charles Mve Mvondo, $M D^{1}$, Silvia Cirri, $M D, P H D^{2}$, Alessandro Giamberti, $M D^{2}$, Gianfranco Butera, $M D, P H D^{2}$ \\ 'St. Elizabeth Catholic General Hospital Shisong Cardiac Centre, Cameroon \\ ${ }^{2}$ Department Of Pediatric Cardiology And Cardiac Surgery San Donato, Italy}

Objective: To create awareness and stimulate the zeal to develop cardio-surgical centres in low income countries.

Background: Within the M.E.C.C.A (Monetary and Economic Community of Central Africa) zone, cardiovascular health is a major asset. The Shisong Cardiac Centre in Cameroon has over the past seven years assisted many clients to regain lost hopes.

Method: A retrospective review of patients who underwent percutaneous interventions, pacemaker implantations and cardiac surgery from January 2010 to June 2017.

Results: Total performance and respective monthly (30-day) mortality rate: Cardiac Catheterizations, diagnostic and interventions: (459), mortality rate $(0.002 \%)$. Pacemaker implantations: (155), mortality rate $(0.007 \%)$.Cardiac Surgery: (643), intra-operative mortality rate(0.004\%)

Discussion: Late presentation at procedures and financial hardship on the part of the population, availability of consumables, human resources, and technical difficulties are amongst the factors that have characterized our experience.

Conclusion: Cardio-surgical centres are possible in low income countries. Challenges are bound to occur but through a collaborative approach, sustainability may be assured. Patient education and a safe sociopolitical atmosphere play vital roles.
(C) 2018 Journal of Structural Heart Disease Published by Science International Corp. ISSN 2326-4004

Fax +1 2037853346

E-Mail: jshd@scienceinternational.org http://structuralheartdisease.org/
Accessible online at: http://structuralheartdisease.org/ 


\section{SHORT AND INTERMEDIATE TERM SAFETY AND EFFICACY OF PERCUTANEOUS DEVICE CLOSURE FOR SECUNDUM ATRIAL SEPTAL DEFECTS USING OCCLUTECH FIGULLA OCCLUDER N \\ Khaled R Abd El Meguid MD', Yaser A Abd Elhady MD', Mohamed M Zaki MSC 3 \\ ${ }^{1}$ Division of Cardiology; Benisuef University Hospital, Benisuef, Egypt ${ }^{2}$ Division of Cardiology; Benisuef University Hospital, Benisuef, Egypt ${ }^{3}$ Division of Cardiology; Benisuef University Hospital, Benisuef, Egypt}

Background:Transcatheter closure has become the method of choice for most patients with secundum ASD. Although the Occlutech device may have some advantageous characteristics there is a paucity of data on outcomes after the use of this relatively new device.

Objectives: To investigate the safety, effectiveness \& hemodynamic effects of percutaneous atrial septal defect (ASD) closure using the Occlutech ${ }^{\circledast}$ devices in a prospective trial.

Methods: Observational, single arm study including 111 patients who underwent ASD closure between October 2013 and December 2015. Device performance, immediate, short and intermediate-term outcomes were assessed.

Results: Median age and ASD size were 7.8 years (8 months-59 years) and $16.5 \mathrm{~mm}(4.8-38 \mathrm{~mm})$ respectively. Deficient or absent retro-aortic rim was observed in 30 patients (27\%). All patients had dilated right side chambers. Pulmonary artery systolic pressure $>$ $35 \mathrm{mmHg}$ was observed in 57 (51\%) patients who had significantly larger ASDs $(p=0.009)$ and larger RV lengths $(p=0.006)$. Implantation of Occlutech device (mean size of $19.4 \pm 8 \mathrm{~mm}$ ) with successful closure was reported in $95.5 \%$. Closure success was linked to larger IVC rims ( $p=0.009$ ). An IVC rim $\geq 7.2 \mathrm{~mm}$ is $97.1 \%$ sensitive, while IVC rim $\geq 11.2 \mathrm{~mm}$ is $100 \%$ specific for closure success. Median follow-up of 6 months was obtained in all patients. Successful closure lead to significant regression of RV \& pulmonary artery dimensions at 1, 3 \& 6-months follow up $(p<0.001)$.

Conclusions: Transcatheter closure of secundum ASDs using the Occlutech septal Occluder is safe, and effective in children, adolescents, and adults. The device performed well in a wide range of anatomical scenarios resulting in excellent short and intermediate-term outcomes. Sufficient IVC rim is the most important factor in predicting successful closure.

\section{SHORT AND INTERMEDIATE TERM SAFETY AND EFFICACY OF PERCUTANEOUS DEVICE CLOSURE HEART SURGERY FOR CONGENITAL HEART DISEASE IN RABAT'S PEDIATRIC HOSPITAL}

Sara Hassani

Rabat's University Hospital, Rabat. Marocco

Background: We aim to report the results of our experience in pediatric closed heart surgery for congenital heart disease in Rabat's pediatric hospital, in a country that suffers from a lack of a strong health infrastructure.
Methods: We conducted a retrospective study of patients that underwent palliative or corrective surgery for congenital heart disease in Rabat's pediatric hospital, in a period of 27 months, from 25 June 2014 to 12 September 2016.

Results: The mean age of our patients ( $n=62$ ) was 2 years 8 months. $62 \%$ were infants, below $\mathrm{X}$ months old. Patent ductus arteriosus was the most frequent non-cyanotic lesion while tetralogy of Fallot was the most frequent cyanotic heart disease. Four patients had congenital dysrhythmia. 35 palliative procedures were performed 12 modified Blalock Taussig shunts, 13 pulmonary arterial bandings) while 33 were curative ( 24 ligations of patent ductus arteriosus, 6 Crafoord interventions and 3 ligations of double aortic arches). 4 patients underwent epicardial permanent pacing. The short-term (mortality rate was $8 \%$, mainly in the group that underwent palliative procedures (a ratio of 4 to 1). Hemodynamic instability was by far the most frequent early complication whereas nosocomial infection was the most reported complication in the medium term. In the longer term, one death was reported a year after surgery in a patient who underwent a BT shunt. One case of residual hypertension was reported in our oldest patient that underwent a Crafoord intervention. 38\% of the patients were lost to follow up while the control was satisfying for $62 \%$ of them. Three of the patients that underwent a Blalock Taussig shunt for a ToF have had a corrective surgery; 2 of them in private structures and one in Rabat's children hospital during a surgical mission by a Swiss team. The patients that underwent PA banding are still waiting for corrective surgery.

Conclusion: Congenital heart disease is still under-diagnosed and undertreated in our country. Our results are encouraging despite the lack of infrastructure and the complexity of the heart disease treated. Our country remains in need of specialized centers with multidisciplinary teams and expert physicians.

\section{BALLOON MITRAL VALVOTOMY IN A PATIENT WITH SITUS INVERSUS DEXTROCARDIA}

\section{Osama Rifaie}

Ain Shams university Cairo' Egypt

Background: A 20 years old female with history of rheumatic fever at the age of 10.Three years ago, she started to note progressive shortness of breath on moderate effort followed by paroxysmal nocturnal dyspnoea and orthopnoea.

On Examination: Pulse $=80 / \mathrm{min}$. regular with good volume, equal on both sides, well felt peripherally and without special character $B P=120 / 80 \mathrm{mmHg}$. Normal jugular venous pressure no leg oedema. Liver was felt $2 \mathrm{~cm}$ below the left costal margin. Apex was in the right fifth space inside the mid clavicular line with slapping character. Auscultation revealed accentuated S1, loud P2+Opening snap+mid diastolic rumble at the apex.

Echo showed Dextrocardia +Situs inversus, Mitral stenosis with mitral valve area $(M V A)=1 \mathrm{~cm}^{2}$ by planimetry without mitral regurgitation (MR).Wilkins score $=8 / 16$, Rifaie score $=2 / 12$.TEE revealed free left atrial appendage( $L A A)+$ thin atrial septum. Balloon mitral valvotomy (BMV) was planned. 
Technical challenges: 1-Right or let femoral vein access. Reverse the fluroscopy screen or not 3-Left atrial and atrial septal orientation 4. Expected difficult crossing of the mitral valve

Technique: Right femoral vein and artery puncture were done. (BMV) was done using the transvenous transseptal approach. Inoue balloon technique was undertaken using $24-26 \mathrm{~mm}$ balloon diameter. Technical tips will be discussed during the presentation.

Result: (BMV) was successfully done without significant complications. Left atrial pressure dropped from 25 to $14 \mathrm{mmHg}$. Pulmonary artery mean pressure dropped from 40 to $20 \mathrm{mmHg}$ Post (BMV) echo showed: Mitral valve area $=1.9 \mathrm{~cm}^{2}$ by planimetry. Mean Doppler gradient $=5 \mathrm{mmHg}$.Moderate mitral regurgitation.
Conclusion: Association of rheumatic mitral stenosis and dextrocardia with situs inversus is very rare. Only few cases were reported in the English literature where (BMV) was done. Despite technical difficulties, (BMV) could still be done in the hands of experienced operators.

\section{Comment on this Article or Ask a Question}

Cite this article as: Hijazi ZM. 2017 CSI Africa Abstracts. Structural Heart Disease. 2018;4(2):66-68. DOI: https://doi. org/10.12945/j.jshd.2018.949.17 